DOI: $10.5433 / 2237-4876.2013 v 16 n 2 p 149$

\title{
Paixão, Mito e Formas de Vida em Textos Publicitários
}

Passion, Myth and Ways of Life in Advertising

Edna Maria Fernandes dos Santos NASCIMENTO *

Envergonhamo-nos de confessar que temos ciume, e sentimo-nos honrados por ter tido e por ser capazes de ter. (La Rochefoucauld, Maximes)

Resumo: A paixão, concebida por Aristóteles como uma contingência que provoca mudança na essência do sujeito, foi objeto de estudo do filósofo grego como uma estratégia retórica utilizada pelo orador para comover seu auditório. A semiótica greimasiana, ampliando o conceito de paixão aristotélica, a concebe como estados de alma de um sujeito que podem ser depreendidos a partir da análise de um texto. Reflexões sobre a discursivização das paixões e sobre seus efeitos de persuasão em textos publicitários conduzem-nos a estabelecer relações entre paixão, mito e formas de vida. Palavras-chave: Texto publicitário. Paixão. Formas de vida.

Abstract: The passion, understood by Aristotle, as a contingency which causes a change in the essence of the subject, was object of research of the Greek philosopher as rhetorical strategy used by the speaker to touch its listeners. The greimasian semiotics, enlarging the concept of Aristotle's passion, understands it as the soul states of a subject that can be gathered form the analysis of a text. Reflections towards the passion discursivization and its

\footnotetext{
* Mestrado (1979) e Doutorado (1987) em Linguística pela Universidade de São Paulo. Livre-docente em Linguística (UNESP, 1997). Atua como professora e orientadora no Programa de Mestrado e Doutorado em Linguística e Língua Portuguesa da Universidade Estadual Paulista Júlio de Mesquita Filho (UNESP-Araraquara). Contato: edna.fernandes@uol.com.br.
} 
persuasion effects in advertisements lead us to establish the relationships between passion, myth and ways of life.

Key-words: Advertisements. Passion. Ways of life.

\section{Introdução}

O estudo das paixões remonta a Aristóteles. Na sua Retórica das paixões, o filósofo grego demonstra que o orador faz uso delas para comover o auditório. Nessa acepção, as quatorze paixões elencadas por ele são estratégias retóricas próprias do discurso oral. Na semiótica greimasiana, a afetividade passa a fazer parte de suas preocupações a partir da publicação de $D e$ l'imperfection (1987). Mais sistematicamente, Greimas e Fontanille postulam um dispositivo canônico comum a todas as paixões no livro Sémiotique de la passion (1991). Ampliando o conceito de paixão aristotélica, a semiótica greimasiana a concebe como estados de alma de um sujeito que podem ser depreendidos a partir da análise de qualquer texto, seja ele verbal, visual ou sincrético, oral ou escrito. Deixando de ser um mecanismo retórico, a paixão para Greimas é um componente do ator que o individua, o torna mais humano e mais semelhante aos seres do mundo natural.

Neste artigo, retomando os apontamentos de Aristóteles e os estudos greimasianos sobre paixão, pretendemos refletir sobre a utilização das paixões em textos publicitários do absorvente Modess publicados na revista $O$ Cruzeiro, estabelecendo relações com mito e formas de vida da mulher da década de 50. Tal reflexão, parece-nos, é bastante produtiva para a análise de textos midiáticos que utilizam, muitas vezes, as paixões reiterativa e hiperbolicamente para convencer ou persuadir o enunciatário e levá-lo à compra do produto anunciado.

\section{Aristóteles e o Ser Bipartido: logos e pathos}

Falar de paixão e ser humano é uma redundância, porque ela é inerente ao indivíduo. Aristóteles, no IV século a.C., já distinguia no ser humano a essência e o acidente. A essência é aquilo que caracteriza um ser dentro de uma espécie e o identifica como uno, enquanto o acidente são os predicados que o tornam múltiplo. Michel Meyer (2000), ao longo do "Prefácio" à Retórica das Paixões de Aristóteles, em texto fundamental para se compreender 
a obra desse filósofo grego, lembra exemplos que elucidam suas proposições: Sócrates é calvo ou não, jovem ou não; mas Sócrates é Sócrates e não pode deixar de sê-lo. Dessa dualidade, continua Meyer, decorre a ambiguidade do ser humano, não há sujeito sem essa contingência que o afeta e o define. Outros exemplos são utilizados pelo estudioso da obra de Aristóteles para dar concretude a esses conceitos: que seria de Sócrates se fosse definido apenas por sua essência, senão a mesma coisa que Platão? Nesse texto introdutório, Meyer esclarece que, para Aristóteles, não há sujeito (portanto, identidade necessária) quando a ele se chega somente por seus atributos contingentes. Os predicados do ser constituem o pathos, que é a voz da contingência, da qualidade que se vai atribuir ao sujeito, mas que ele não possui por natureza, por essência. É pelo pathos, pela paixão, que o sujeito sai de si, da sua própria identidade, ou mesmo perde sua identidade, por isso o pathos escapa ao logos, que é a identidade redutora do sujeito. O dualismo pathos x logos, embora complementares entre si, opõe dois sujeitos díspares que provocam um drama próprio da condição humana. É pela paixão que o ser humano exprime e mede sua identidade e diferença.

As reflexões de Meyer sobre as concepções de essência e acidente facilitam a compreensão da definição de paixão sob a ótica de Aristóteles, que a concebe como uma contingência que provoca mudança na essência do sujeito, sendo, então, a expressão da sua temporalidade. Lemos em Aristóteles:

As paixões são todos aqueles sentimentos que, causando mudança nas pessoas, fazem variar seus julgamentos, e são seguidos de tristeza e prazer, como a cólera, a piedade, o temor e todas as outras paixões análogas, assim como seus contrários. (ARISTÓTELES, 2000, p. 5).

No estudo das paixões, Aristóteles distingue sempre três pontos de vista. Dando prosseguimento ao estudo dos três pontos de vista das paixões - disposição das pessoas apaixonadas, objetos e motivo das paixões -, Aristóteles (2000, p. 5) fecha o capítulo 1, intitulado "Do caráter do orador e das paixões do ouvinte", da Retórica das paixões, explicitando que o orador deve dominá-los para atingir o ouvinte:

Devem-se distinguir, relativamente a cada uma, três pontos de vista, quero dizer, a respeito da cólera, por exemplo, em que disposições 
estão as pessoas em cólera, contra quem habitualmente se encolerizam, e por quais motivos. De fato, se conhecemos apenas um ou dois desses pontos de vista, mas não todos, seria impossível inspirar a cólera; o mesmo acontece com as outras paixões.

O objetivo de Aristóteles ao distinguir as 14 paixões - cólera, calma, amor, ódio, temor, confiança, vergonha, impudência, favor, compaixão, indignação, inveja, emulação, desprezo - é, sobretudo, caracterizá-las e diferenciá-las para que o orador possa convencer e persuadir seu auditório, como se pode observar ao lermos o parágrafo que encerra o capítulo sobre paixões: "Eis o que tínhamos a dizer sobre os meios pelos quais surgem e cessam as paixões, fontes de onde se tiram os argumentos retóricos." (ARISTÓTELES, 2000, p. 73)

\section{Semiotização das Paixões}

Sabe-se que, por influência de Ferdinand de Saussure, a Linguística de cunho estruturalista eliminou de seus estudos o sujeito. Vale lembrar que esse ser que torna a língua discurso, embora banido do Curso de Lingüistica Geral (SAUSSURE, 1970), aflora nos anagramas e em outros estudos saussurianos. Obumbrado durante anos pelos estudos linguísticos, o sujeito aparecia de forma escusa quando se viam ou se ocultavam suas marcas em textos classificados, respectivamente, como subjetivos e objetivos. Mas essa tipologia era centrada intrinsecamente no texto, não se reconhecia uma instância aquém ou além do texto que pudesse viabilizar a passagem da língua ao discurso. Com os estudos de Émile Benveniste, que postula a enunciação como "Este colocar em funcionamento a língua por um ato individual de utilização" e conclui que " $\mathrm{O}$ ato individual de apropriação da língua introduz aquele que fala em sua fala" (BENVENISTE, 1989, p. 82-84), o sujeito retorna explicitamente como objeto de estudo da Linguística.

O modelo do percurso gerativo do sentido proposto por Greimas, na década de 60, utiliza-se do conceito de enunciação benvenistiano e o propõe como um conversor do nível narrativo para ao discursivo. É o sujeito da enunciação que se desdobra em enunciador e enunciatário que produz o simulacro do discurso. Mas por muito tempo, certamente por influência estruturalista, a preocupação dos semioticistas centrou-se no nível narrativo, descrevendo programas narrativos de que participavam os modelos 
lógicos actanciais: destinador/destinatário, sujeito/objeto, coadjuvante/ oponente. Reconhecia, então, a semiótica a dimensão pragmática do texto, em que um sujeito de estado, modalizado pelo ser, já competente, modalizava-se pelo fazer. Com esse percurso que simulava a narrativa do sujeito no mundo, com todas as perdas e danos, a semiótica objetivava dar conta de como o texto faz para dizer o que diz. Postulando que o texto estabelece um contrato de fidúcia entre enunciador e enunciatário, interessavase também a semiótica pelos mecanismos que criam o efeito de veridicção, ou seja, como o texto faz para ser interpretado como verdadeiro. A essas duas dimensões, a pragmática em que o sujeito é modalizado pelo fazer e a cognitiva em que o sujeito é modalizado pelo saber parecer verdadeiro, é acrescentada uma terceira, na década de 80: a dimensão patêmica.

Partindo do conceito etimológico do termo paixão, proveniente de pathos, que significa o que chega bruscamente, ou em sentido mais particular sofrimento e dor, e da concepção filosófica aristotélica, que a identifica como o estado contingente daquele que recebe uma influência exterior, em Semiótica das paixões, Greimas e Fontanille definem as paixões como estados de alma.

Estudos mais recentes de semiótica buscam determinar quais as modalizações que, modificando o sujeito, imprimem nele comportamentos passionais. Para a semiótica, portanto, as paixões são produtos dos efeitos de sentido de qualificações modais que modificam o sujeito de estado. $\mathrm{O}$ actante, modelo lógico do nível narrativo, que se antropomorfiza no nível discursivo, ao ganhar um papel temático, aproxima-se mais do mundo natural quando a semiótica delimita seu papel patêmico e se propõe a estudar as organizações dos arranjos sintagmáticos das modalidades passionais que caracterizam as configurações próprias de cada paixão, manifestadas em forma de texto. Fontanille e Greimas (1993, p. 244) propõem um esquema passional canônico análogo ao do nível narrativo:

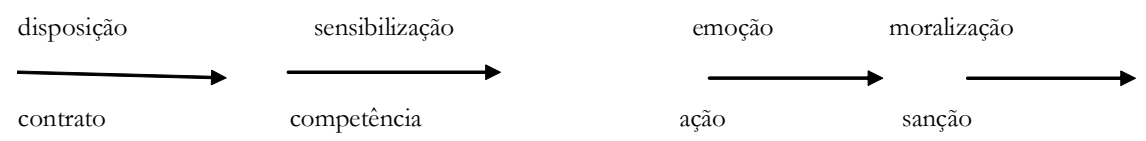


$\mathrm{Na}$ "disposição", o sujeito apaixonado manifesta seu "estilo" rítmico, que se caracteriza pelo abalo e pela inquietude; na "sensibilização" define-se a sua competência principal e se instala um tipo de paixão. A "emoção", por sua vez, é a manifestação pública do estado afetivo, e é na "moralização" que o sujeito apaixonado restabelece com o espaço social as normas e usos em curso. Como podemos observar pelo esquema passional, as paixões só fazem sentido se forem homologadas em uma práxis social e, como tal, elas se manifestam em forma de linguagem, não sendo, pois, da ordem do natural, mas do cultural. A estrutura passional, lembra Denis Bertrand (2003, p. 430), é controlada pela moralização, isto é, pela regulação social que estabelece a medida, entre excesso e insuficiência, da circulação dos valores.

$\mathrm{O}$ ator, que até antes da semiótica das paixões era definido como a junção de no mínimo um papel actancial e de um papel temático, com o esquema passional canônico aproxima-se mais do ser humano de carne e osso, ficando mais complexo quando lhe é atribuído um papel patêmico.

Considerada do ponto de vista da instância enunciante (BERTRAND, 2003, p. 430), a paixão submetida à inerência do corpo e do mundo sensível é uma forma de não-sujeito: o passional predica, mas falta-lhe o juízo que transforma a predicação em uma assertiva assumida e refletida. A paixão opõe-se, nesse caso, à razão.

\section{Paixão como Forma de Vida}

A concepção de forma de vida utilizada por Greimas (1993) provém de Wittgenstein (1975), que a concebia como a maneira pela qual os indivíduos e os grupos exprimem sua concepção de existência por meio das maneiras de fazer e ser, de consumir e arrumar o espaço em que vivem. Greimas, partindo da concepção wittgensteiniana, explica que uma forma de vida está aliada a um comportamento esquematizado mais profundo que representa não o estilo individual, mas uma filosofia de vida de um determinado grupo cuja ruptura provoca uma mudança radical de forma de vida. Para Greimas (1993, p. 33), uma forma de vida define-se:

(1) por sua recorrência nos comportamentos e no projeto de vida do sujeito, (2) por sua permanência [...], (3) pela deformação coerente que ela induz a todos os níveis do percurso de individuação: nível sensível e tensivo, nível passional, nível axiológico, nível discursivo e aspectual etc. 
Com o estudo das formas de vida, Greimas busca dar conta do movimento da própria vida, ou seja, do sentido da vida, concebido como que direção a vida toma. Os usos cristalizados em dispositivos que configuram formas de vida passam a ser uma das tarefas da semiótica, como comenta Fontanille na "Apresentação" (1993, p. 9.) do dossiê do último Seminário de Semântica Geral de Algirdas Julien Greimas na École des Hautes Études en Sciences Sociales - E.H.E.S.S., consagrado à "Estética da ética" 1 :

Uma das tarefas da semiótica poderia ser examinar em quais condições esses dispositivos se estabilizam e se desestabilizam para produzir 'regras de interpretação' locais, idioletais ou socioletais, estereótipos e protótipos, esses 'praxemas' que são remetidos em seguida na cultura e disponíveis para novas convocações. ${ }^{2}$

Fontanille (1993, p. 9) afirma que, para empreender tal tarefa, na perspectiva da práxis enunciativa, é preciso determinar quais são as unidades discursivas engendradas pela práxis e manipuladas nos discursos realizados e apreender os parâmetros sobre os quais a práxis opera para modificar essas unidades tipos ou para criar novos.

Como primeiros trabalhos de apreensão e de criação de novos parâmetros das formas de vida, a revista Recherches Sémiotiques Semiotic Inquiry (1993) apresenta textos em que se estudam diferentes dispositivos: do belo gesto, de A. J. Greimas; da justiça, de D. Bertrand; da cilada, de T. M. Keane; das formas de alteridade, de E. Landowski; do absurdo, de J. Fontanille; da sensibilidade e individualização, de Marks, L.R.

Esses estudos, como observa Fontanille (1993, p. 11), no final da "Apresentação", demonstram que como fundamento de toda forma de vida encontra-se um estado de alma: “[...] a desconfiança gerada por uma 'cilada', o estupor e a depressão pelo 'absurdo', a paixão do equilíbrio pela 'justiça'. A própria 'marginalidade' confronta dois estados de alma, um

${ }^{1}$ O Seminário de Semântica Geral realizou-se de 1991 a 1992 em Paris, e Greimas morre em fevereiro de 1992. A temática "Estética da ética: moral e sensibilidade" foi sugerida por Greimas e os textos resultados desse encontro foram organizados por Jacques Fontanille e publicados sob o título Les formes de vie, na revista Recherches sémiotiques. Semiotic inquiry - RSSI (1993).

2 As traduções de obras sem tradução em língua portuguesa são de nossa autoria. 
coletivo e um outro individual, e ela nutre entre outros movimentos o de repulsão."

O estado de alma fundamental de cada forma de vida pode ser visto como um sintoma de intencionalidade específica ligada à própria forma de vida. Segundo Fontanille (1993, p. 12) uma grande parte da semiótica narrativa foi construída em torno de uma única forma de vida, procedendo de um único tipo de intencionalidade: a da busca, organizada e convocável em discurso graças ao sintagma-tipo, que é o esquema narrativo canônico. Com a teoria das modalidades e das paixões surgem outros caminhos, outras maneiras de "dar sentido à vida" emergem e a semiótica tem de dar conta dessas variedades de paixões que conformam formas de vida.

\section{Formas de Vida e Semiótica das Culturas}

No último seminário de que participou, pouco tempo antes de sua morte, Greimas explicita muito claramente que a descrição das formas de vida deve ocupar um lugar privilegiado na teoria semiótica, porque ela permite a articulação entre o sensível e o inteligível. As formas de vida, apesar de se tornarem um comportamento esquematizado, estereotipado de um indivíduo ou de um grupo, podem sofrer uma ruptura, provocando uma nova percepção sobre o mundo, uma estesia, que, acarretando uma nova visão de mundo, configura uma nova forma de vida. Nesse caso, a moral social que identifica o sujeito com um grupo pelo seu saber-fazer é substituída pela individual modalizada pelo saber-ser. Nas palavras de Greimas (1993, p. 23): "Face a essa moral social, pode se desenvolver uma moral pessoal, na medida em que os saber-fazer são suscetíveis de se transformar em saber-ser. Nesse caso, o acento é colocado sobre a 'maneira de fazer', relegando assim para o segundo plano a simples realização do objetivo, que é da alçada unicamente do saber-fazer".

O exemplo do belo gesto empregado por Greimas para mostrar a articulação entre o inteligível e o sensível, elucida essa passagem do saber-fazer para o saber-ser. Escreve o autor (1993, p. 34) que o belo gesto do cavaleiro que se nega a entrar no jogo amoroso da dama ou de Jesus que incita a população a jogar a primeira pedra em Madalena se houver alguém entre eles que nunca pecou é uma invenção por negação: negação de uma moral social fundada sobre a mudança, negação de um sistema de valores cuja valência é função dos desejos da coletividade, negação de programas 
narrativos cujo desenvolvimento em processo é dessemantizado e dessensibilizado. Portanto, ainda segundo o semioticista lituano, no mesmo texto, o belo gesto é a invenção de uma ética individual não reproduzível, de um universo de valores aberto sobre múltiplos possíveis ainda indeterminados, é a invenção de formas de vida que se instalam, pouco depois da negação fundadora, graças a uma nova afirmação que imporá suas determinações. Da análise do belo gesto que provoca uma estesia e uma negação de uma forma de vida e a manifestação de outra, Greimas (1993, p. 34) conclui: "Desse ponto de vista, o belo gesto é sem dúvida o melhor exemplo (o protótipo) de uma articulação da estética com a ética, pela qual o valor de uma conduta tornou-se sensível através de uma maneira de ser ou de fazer".

Greimas (1993, p. 23) conclui ainda que, relegando para segundo plano a simples realização de um objetivo, isto é, o sujeito movido apenas pelo saber-fazer, há o privilégio, nesse caso, da "maneira de fazer", ou seja, o sujeito é considerado como modalizado, é a "maneira de ser fazendo" sob a forma de um saber-ser.

Essa mudança de nível, do saber-fazer para o saber-ser, apresenta duas características particularmente interessantes para a semiótica; acrescenta Greimas (1993, p. 23-24):

Primeiramente, ela abre-se para a dimensão passional, ao menos potencialmente, porque a conversão das modalidades do fazer em modalidades do ser do sujeito está na origem, no nível da sintaxe narrativa, de todos os efeitos de sentidos passionais. Em seguida, ela abre para a dimensão estética, porque o saber-ser, concebido como 'maneira de fazer', pode aparecer como a emergência de um plano de expressão, constituído pela modalização do ser, relacionado a um plano de conteúdo que seria constituído pela modalização do fazer. A 'maneira de ser' seria então do domínio da manifestação sensível (liberando para isso um 'parecer'), ao passo que a eficácia própria do saber-fazer seria da ordem da imanência cognitiva, a ser reconstruída a partir do resultado final do percurso.

Vemos pela última exposição de Greimas, expressa no texto Le beau geste (1993), que o projeto greimasiano visa a dar conta não de uma única forma de vida, mas busca as variedades de formas de vida geradas pela interação com o outro no cotidiano, seja ele um sujeito ou um objeto. 
$\mathrm{Na}$ concepção greimasiana, uma forma de vida desenha um perfil identitário próprio a um indivíduo, um grupo ou uma cultura. Portanto, se a forma de vida se manifesta necessariamente pela recorrência, pela regularidade, uma exceção força a atenção: a do belo gesto que, precisamente, transgride a regra estabelecida, "desfaz uma fixidez, estetiza e torna sublime um renovamento dos valores" (COLAS-BLAISE, 2012, p. 15) pela brutalidade de sua força singular.

Nessa perspectiva, a cultura pode ser pensada como um conjunto de formas de comportamentos adquiridos nas sociedades humanas e, nesse sentido, segundo Colas-Blaise (2012, p. 23), ela é uma arquiforma de vida. Em razão da força de ruptura que caracteriza a forma de vida, continua a autora, a cultura é movente e deve ser concebida no seu devir, como uma "cultura viva". A forma de vida, na concepção greimasiana, torna-se para a semioticista uma manifestação privilegiada, porque ela assume um papel motor para a cultura. Lembra a autora que, se as culturas se modificam em contato com outras culturas, elas integram também uma dinâmica interna pela qual a forma de vida é largamente responsável. Assim concebida, a forma de vida, ainda de acordo com Colas-Blaise (2012), é compatível com um pensamento do sujeito que, triunfando tanto do objetivismo estrutural como de uma tradição "humanista", que reconhecia no sujeito intenções reprimidas, faz praticar a fundo a dialética do coletivo e do singular, da permanência e da novidade e não é necessário muito para que a forma de vida possa mudar, verdadeiramente, o "sentido da vida" (COLAS-BLAISE, 2012, p. 23-24).

A forma de vida, na perspectiva do projeto greimasino, constitui-se em um nível de descrição das gestões dos valores culturais identitários próprios ou do outro. Portanto, a forma de vida não é jamais natural, mas uma construção cultural individual e coletiva que se encarrega do sentido da vida, conforme Beyaert-Geslin (2012, p. 1), e é a forma de vida que faz viver a cultura, segundo Fossali (2012, p. 22).

\section{Publicidade e Escolha de Formas de Vida}

Essas reflexões sobre o conceito de paixão de Aristóteles, sobre a proposta greimasiana de semiotização dos estados de alma do sujeito e sobre o conceito de formas de vida nos permitem estabelecer relações entre paixão, mito e formas de vida em textos publicitários. 
No artigo L'innovation alimentaire et le monde des OCNI, ${ }^{3}$ Boutaud (2005, p. 25), comentando sobre produtos novos que o texto publicitário coloca em circulação, observa que, em um mercado de grande consumo, de concorrência e competição, a busca da inovação é não somente necessária, mas também vital para a sobrevivência das indústrias e das marcas. Para que o enunciatário incorpore o novo objeto, é necessário que ele seja apresentado de maneira mais sensível e que sua dimensão epistêmica seja menos focalizada, despertando um contrato fiduciário antes mesmo de ser usado. Tendo como meta a venda do produto, o texto da mensagem tem de criar um universo de referência em que há um consumo efetivo do produto, como contar uma historinha bem sucedida de uma pessoa que fez uso dele, por exemplo, ou apresentar o sujeito em êxtase ao usá-lo, ou juntar as duas situações. Com essas estratégias, lembra Boutaud (2005, p. 27), a inovação estabelece também um contrato identitário entre a marca ("Isso vai mudar") e o enunciatário ("Isso vai mudar você"). Operando com essa manipulação, a inovação não quer submeter a competência do enunciatário somente ao uso do produto, mas a uma nova escolha de vida. É o que conclui Boutaud (2005, p. 32):

Em um mercado hipersensível para as marcas, o aparecimento de um novo produto não se reduz a uma proposição comercial. Por meio do objeto desenha-se a construção identitária do consumidor, suas modalidades de ser e de fazer, ou mais ainda, suas escolhas de vida orientadas para uma forma de vida. No nosso contexto cultural, a relação com o objeto alimentar toma, por conseqüência, a forma mais ou menos consciente de um contrato que coloca em jogo a identidade e a imagem do comedor além de suas necessidades.

Em resumo, podemos dizer com Boutaud (2005, p. 49) que o objeto não está simplesmente situado em um espaço objetivo e dotado de propriedades intrínsecas, como peso, volume, cor, porque “[...] ele existe no interior de uma prática, quer ela seja identificada ou não, o que significa para nós que ele é sempre aprendido por um sujeito colocado como corpo em movimento." As afirmações de Boutaud são importantes e nos dão respaldo para mostrar que, no discurso publicitário, o produto, por suas características,

${ }^{3}$ OCNI é a sigla de Objetos Comestíveis Não Identificados (BOUTAUD, J.-J, 2005, p. 36). 
é apresentado como um objeto útil no cotidiano de um indivíduo, ou, em outras palavras, todo objeto tem um valor pragmático, serve para fazer alguma coisa, mas, sendo também social, ele circula entre corpos que também por se moverem obedecem a práticas semióticas que, regulando seu uso, lhe atribuem um segundo valor. Nesse sentido, podemos concluir que cada publicidade valoriza o uso do objeto, tornando-o um objeto-valor que, além de ter um valor prático, adquire um valor mítico de um sonho que pode ser realizado. Contribuindo para que o produto seja apresentado de uma forma esteticamente a mais agradável possível, as publicidades, segundo nosso ponto de vista, convertem-se numa possível realização: o objeto adquire o poder de transformar a forma de vida de quem o utiliza. Isso ocorre porque as cenas enunciativas das publicidades exploram o sensorial do produto e hiperbolizam suas características, despertando emoções no enunciatário, com a finalidade de alterar seu não-querer em dever-querer. A modalidade deôntica dever reforça o porquê de se consumir o produto. Ao objeto-valor apresentado pelas publicidades sobrepõe-se o valor do valor, que expressa diferentes regimes de presença no mundo que o produto enunciado quer impor ao enunciatário. Ser mais antiquado ou mais moderno, por exemplo, implica uma forma de presença no mundo, uma forma de vida que determina não só a construção de um sujeito, mas também reconstitui o espaço e o tempo em ele que vive. As publicidades são, portanto, reveladoras de como se dá a interação dos objetos com os sujeitos na vida cotidiana e de quais são as imposições determinadas pelo seu uso que configuram formas de vida a que subjazem comportamentos patêmicos. O sujeito figurativizado como antiquado em uma publicidade é reconhecido por incorporar valores indicativos da tradição, enquanto o moderno é identificado como aquele sujeito que sempre está aberto para novos valores; eles figurativizam respectivamente um discurso do tempo passado e do tempo presente. Nos discursos publicitários, o uso de um novo produto que substitui um velho, ou de uma nova marca, simula um enunciatário que pertence a um grupo social que tem implicitamente um estado de alma propenso à paixão da aventura, que se opõe à paixão da prudência daqueles que se negam à nova experiência. 


\section{Estados de Alma e Formas de Vida na Publicidade: dimensões estética, estésica e ética}

Volli (2003, p. 41, grifos do autor) observa:

O discurso publicitário, sempre que é produzido, anuncia-se dizendo implicitamente que falará de qualquer coisa, mas com o objetivo de exaltar os valores de uma marca, de nos levar a adquirir um produto ou a adotar um dado comportamento: contar-nos-á uma história divertida, dar-nos-á um exemplo instrutivo, mostrar-nos-á uma imagem sensual, exibir-se-á com uma piada, exibirá uma série de dados 'objetivos', pedirá nossa cumplicidade a fim de atingir o objetivo de modificar a nossa atitude perante o tema publicitado.

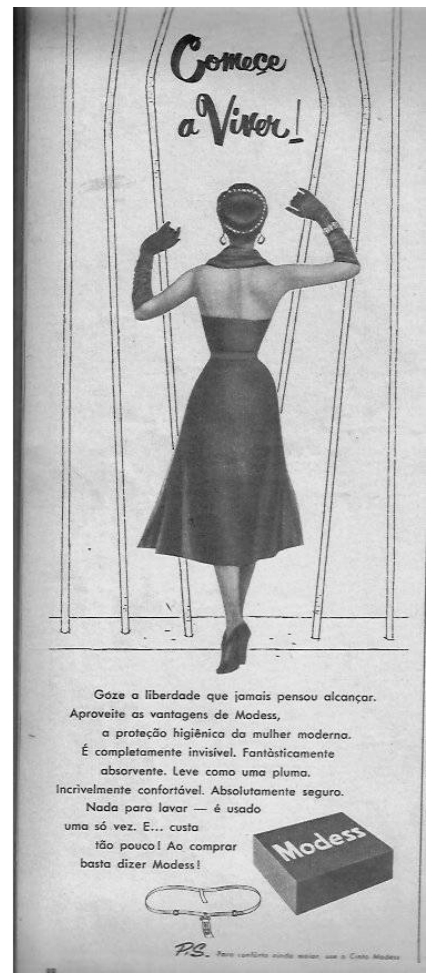

Texto da publicidade:

COMECE A VIVER!

Góze a liberdade que jamais pensou alcançar. Aproveite as vantagens de Modess,

a proteção higiênica da mulher moderna.

É completamente invisível. Fantàsticamente absorvente. Leve como uma pluma.

Incrìvelmente confirtável. Absolutamente seguro.

Nada para lavar — é usado

uma só vez. E... custa

tão pouco! Ao comprar

basta dizer Modess! 
A citação de Volli orienta-nos para refletir sobre a importância da análise de textos publicitários, que sob a dimensão do estético que produz o belo e que apela para a dimensão sensível do enunciatário, despertando sensações emocionais do encontro do objeto, subjaz o bom de uma época, uma ética que identifica grupos conformados por modelos de formas de vida.

De fato, o texto publicitário distingue-se dos demais por trabalhar sempre e principalmente tendo em vista uma forte axiologia. Para tanto, usa ricas estratégias narrativas verbais e visuais, estruturas retóricas articuladas, de modo a valorizar positivamente objetos (produtos, serviços, marcas) e comportamentos que se encontram no mundo natural. Há, então, nesse tipo de texto, uma hiperbolização tanto do componente estético - o produto deve parecer belo - como do componente ético - ele deve ser bom - e do componente estésico - ele deve ser sentido como belo e bom por um determinado enunciatário que retém uma forma de vida.

Assim, por exemplo, o sujeito mulher da publicidade do absorvente higiênico Modess, publicada na revista O Cruzeiro, na década de 50, envolvido pelo conforto, segurança e tranquilidade que o produto lhe proporciona, apresenta-se a nós como um ser inebriado por seu próprio corpo. Por meio do corpo sensibilizado pelo produto, o sujeito mulher se faz presente, se deixa ver, se relaciona com o outro, estabelecendo regimes de presença, segundo Landowski (2004, p. 189, grifos do autor), que configuram o modo como sentimos e vivemos o mundo:

De fato, o regime de presença no 'mundo em que vivemos' comanda o regime de sentido segundo o qual, para o sujeito, o mundo pode significar. Mas, em compensação, o mundo-objeto é ele mesmo um mundo sensível, cujo modo de presença em relação a nós condiciona a maneira como nós o vivemos, e, por isso, nosso grau de disponibilidade frente a ele, enquanto lugar de emergência potencial de um sentido.

Desse modo, o contato estésico com os diferentes tipos de produtos que as publicidades nos revelam, possibilita-nos determinar diferentes formas de vida, segundo a concepção de Landowski (2004, p. 189, grifos do autor): 
A análise das 'formas de vida' que os sujeitos adotam, isto é, em última instância, a explicação de seus regimes de presença no mundo não pode se separar, portanto, de uma análise que tem correlativamente por objeto as propriedades de ordem estésica imanentes aos objetos (discursos ou imagens, seres animados ou coisas), se ela faltasse seria impossível dar conta dos diversos modos segundo os quais eles se dirigem a nós e nos fazem ser o que, por meio de seu contato, nos tornamos.

E, também considerando a importante conclusão a que chega Fontanille (1993, p. 11), na apresentação da Revista Recherches Sémiotiques Semiotic Inquiry, de que como fundamento de toda forma de vida, encontra-se um estado de alma, podemos buscar os comportamentos patêmicos demonstrados pelos sujeitos ao se relacionarem com o objeto proposto para ser consumido.
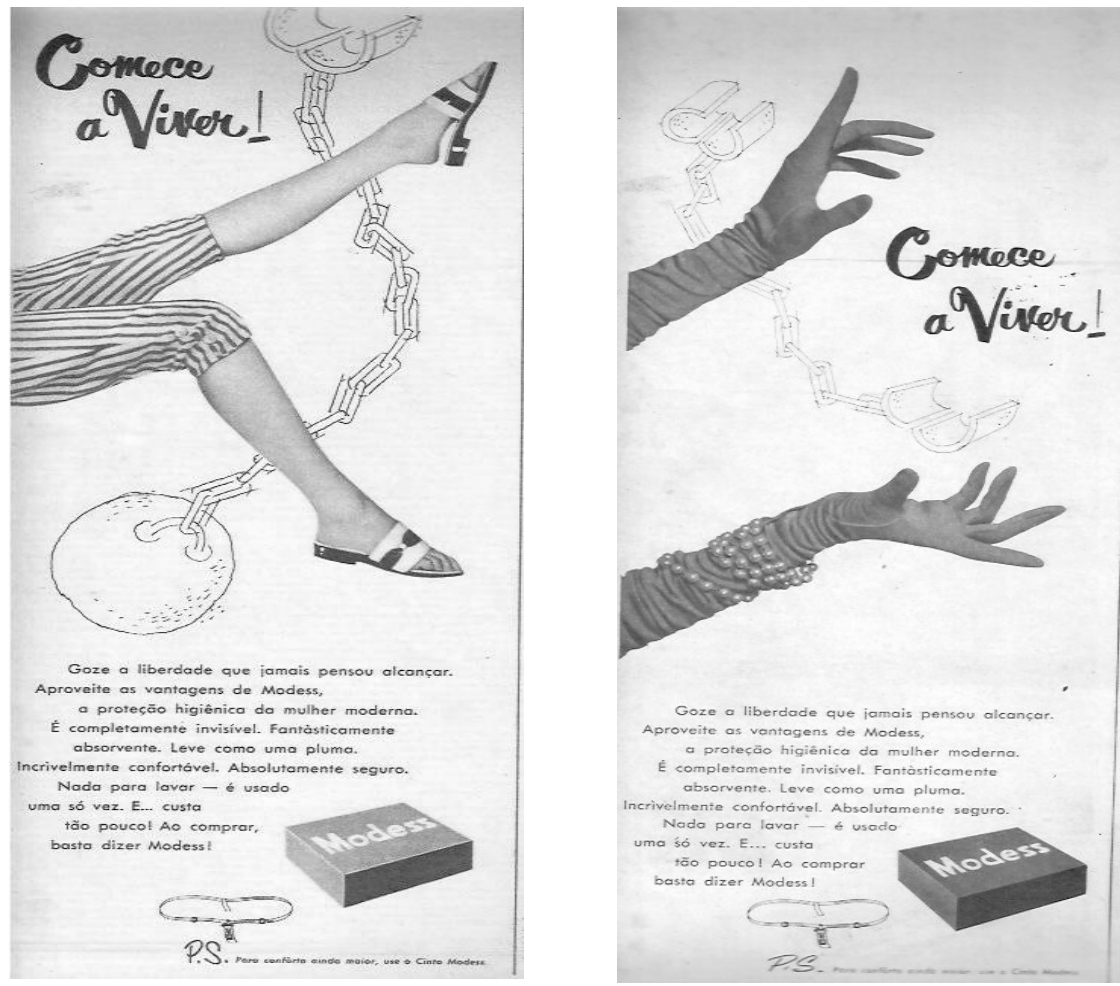
A mulher na publicidade de Modess do nosso exemplo experimenta o êxtase do momento único de liberdade proporcionada pelo absorvente, figurativizado no texto pelo ato de arrebentar as grades que a separam do convívio social "naqueles dias". Outras publicidades do mesmo absorvente, também publicadas na revista $O$ Cruzeiro da década de 50, apresentam o mesmo texto verbal que hiperboliza o produto e são encabeçadas pelo mesmo enunciado exclamativo: “Comece a viver!”. Mesmo não aparecendo o corpo inteiro da mulher, como na primeira publicidade, a cena enunciativa do ato de soltar as algemas das mãos ou os grilhões das pernas, das outras duas publicidades, figurativiza metonicamente o conforto e o bem-estar que o produto lhes proporciona. Flagradas no limiar da liberdade, essas mulheres extasiadas (LANDOWSKI, 2002, p. 150), modalizadas pelo sentir, mostram-se no próprio ato de descoberta da liberdade, configurando sujeitos possuídos por ela.

As cenas enunciativas das publicidades instauram uma ruptura do uso, do comum, do cotidiano, da rotina que leva à emoção estética. Cada publicidade figurativiza para os enunciadores da revista a experiência sensível de um belo momento, uma forma de vida onde a conjunção com o inesperado é infinita, onde a estesia é a regra. Landowski, retomando o conceito de fratura de Greimas (1987, p. 16), explica este momento estético que se constitui em uma descontinuidade na continuidade da existência:

[...] um verdadeiro milagre destinado a preencher essa espera, uma aparição súbita e deslumbrante que vem inopinadamente provocar o êxtase do sujeito, fazendo-o entrever, para além da banalidade das aparências, um mundo 'outro', carregado de sentido. É o momento estético propriamente dito, em completa ruptura com tudo aquilo que o precedeu, bem como com tudo aquilo que o sucederá. De fato, o acidente estético, essa 'fratura' na ordem das coisas, introduz no fluxo de uma continuidade considerada como imutável e necessária uma súbita descontinuidade, tão imprevisível quanto efêmera. (LANDOWSKI, 2005, p. 96)

Mas, ao mesmo tempo, as publicidades apontam para uma forma de vida prática. Elas nos dão os dois lados da moeda da forma de vida do sujeito que oscila entre pequenos momentos de estesia e grandes momentos de anestesia da vida cotidiana como qualquer ser humano, como comenta Landowski (2005, p. 96) no excerto a seguir: 
[...] mal chegado o instante de deslumbramento, começa a inelutável volta ao ponto de partida, a recaída no mundo banalizado e automatizado de todo os dias [...] cuja sucessão em forma de ida e volta nada mais faz, na realidade, do que traduzir no plano sintagmático uma articulação paradigmática estritamente binária: de um lado, a experiência estética, apresentada como um 'relâmpago passageiro', e de outro, o ramerrame do cotidiano, reino de anestesia, do qual o sujeito emerge somente um instante para, logo a seguir, novamente mergulhar nele.

À estesia contrapõe-se uma forma de vida anestesiada, em que afloram, como nos exemplos da publicidade de Modess, os bastidores da vida da mulher dos anos 50 que vive o sentir ser mulher. As mulheres das publicidades são construídas como objeto do desejo, do querer-ser do enunciatário, porque adquirem competência para realizar um programa narrativo de busca da felicidade, do bem-estar. No nível da aparência, a mulher busca a sensação, o sentir conforto, segurança em todos os dias do mês, a fim de que ela possa desempenhar diferentes papéis temáticos, mas, no nível da essência, ela desenvolve um programa de busca em que subjaz uma forma de vida livre em que vida não seja sinônimo de prisão, mas de liberdade e sucesso. As publicidades simulam para as mulheres não usuária de Modess, que viviam presas "naqueles dias do mês", um percurso para a liberdade e sinalizam para aquelas que incorporarem o uso do absorvente como hábito que elas desfrutarão de uma vida moderna. A essas figuras femininas do nível discursivo do texto publicitário subjazem categorias lógicas do nível profundo a que corresponde o percurso da morte para a vida. As publicidades de Modess, que simulam a interação da mulher com um simples objeto do cotidiano, demonstram que novas práticas assumidas pela mulher da década de 50 alteram seu querer, seu sentir, seu saber, seu fazer, identificando uma nova forma de vida mais livre.

O programa de busca do inesperado, da estesia que abala o ramerrame do cotidiano é próprio da condição humana. $\mathrm{O}$ enunciador, ancorando as publicidades em um espaço e um tempo mais modernos, constrói isotopias que, provocando estesia, conduzem o enunciatário para o mundo maravilhoso que o produto pode lhe proporcionar. Seu querer é estimulado a atingir o comportamento patêmico de liberdade que o sujeito mulher das publicidades figurativiza ao usar Modess. 


\section{Conclusão}

Os textos publicitários, como o texto verbal do orador da época de Aristóteles, põem, diante do enunciatário, diferentes aventuras em que ora ele é colocado à prova, ora é estimulado pelo medo, pela raiva, pela gula, ora experimenta sensações de plenitude e liberdade, como no exemplo do absorvente, que, mexendo com as paixões, o convence pela razão, o persuade pela emoção. O que Aristóteles se dispõe a mostrar explicitamente, segundo Meyer (2000, p. XLI), em sua Retórica das paixões é que "As paixões constituem um teclado no qual o bom orador toca para convencer". Na leitura da obra do filósofo grego e nas palavras que citamos de Meyer é possível observar que Aristóteles, ao distinguir e caracterizar cada paixão, as concebe como uma estratégia retórica: seu alvo é a sensibilização do público.

A semiótica greimasiana, complementando os estudos aristotélicos, procura explicitar, a partir de um texto, a discursivização de uma paixão, flagrando como um sujeito, construído por um texto, foi sensibilizado por uma paixão. O estudo das paixões, conforme a teoria semiótica, explica a organização semântica da narrativa e os estados de alma do sujeito, a tensão/ distensão, a euforia/disforia, que o modificam no desenrolar de uma narrativa.

O texto, em geral sincrético das publicidades objeto de nossa reflexão neste artigo, na sua dimensão imagética e verbal é impregnado de emoções que configuram diferentes tipos de paixão. As cenas enunciativas que simulam essas paixões têm o objetivo de transformar o não-querer do enunciatário em dever-querer. Nesse sentido, as publicidades revelam imposições deônticas de uma época que conformam formas de vida: deve-se ter tal carro, viajar por tal companhia aérea, usar tal programa de computador, tal creme, tal absorvente, assistir à televisão em tal aparelho, etc.. Esses objetos da paixão têm o seu valor de uso, servem para locomoção, agilizam a escrita, conservam a juventude, proporcionam conforto, presentificam acontecimentos, mas, além deste valor pragmático, ao utilizá-los, os enunciatários entram em conjunção com os valores míticos que eles representam: poder, sucesso, modernidade, beleza, liberdade. Ao valor prático do produto, as estratégias da publicidade acrescentam o valor mítico do sonho realizado conforme uma maneira de enxergar e estar no mundo. Ser seduzido por um produto é ser seduzido por uma forma de vida que ele proporciona. $\mathrm{O}$ uso do produto identifica o enunciatário com o grupo que 
o utiliza e presentifica uma forma de estar no mundo, uma forma de vida a que subjaz uma paixão.

\section{Referências}

ARISTÓTELES. Retórica das paixões. São Paulo: Martins Fontes, 2000. BENVENISTE, E. Problemas de Lingüistica Geral II. Campinas: Pontes, 1989.

BERTRAND, D. Caminhos da semiótica literária. Bauru: EDUSC, 2003.

BEYAERT-GESLIN, A. Présentation du dossie. Noveaux actes sémiotiques, Limoge, n. 115, p. 1-4, 2012. Disponível em: <http:// revues.unilim.fr/ nas/sommaire.php?id=4076>. Acesso em: 15 ago. 2012. (Atualmente, disponível em: <http://epublications.unilim.fr/revues/as/2630>).

BOUTAUD, J-J. L'inovation alimentaire et le monde des OCNI. In: FONTANILLE, J.; ZINNA, A. (Orgs.). Les objets an quotidien: nouveaux actes sémiotiques: recueil. Limoges: Pulim, 2005. p. 25-38.

COLAS-BLAISE, M. Forme de vie et formes de vie: vers une sémiotique des cultures. Noveaux actes sémiotiques, Limoge, n. 115, p. 1-26, 2012.

Disponível em: <http:// revues.unilim.fr/nas/sommaire.php?id=4076>. Acesso em: 12 ago. 2012. (Atualmente, disponível em: <http:// epublications.unilim.fr/revues/as/2631>).

FONTANILLE, J.; GREIMAS, A. J. Sémiotique de la passion: des états de choses aux états d'âme. Paris: Seuil, 1991.

FONTANILLE, J. ; GREIMAS, A. J. Semiótica das paixões: dos estados de coisas aos estados de alma. São Paulo: Ática, 1993.

FONTANILLE, J. Présentation. Recherches sémiotiques. Semiotic Inquiry, Montreal, v. 13, p. 5-20, 1993.

FOSSALI, P. B. Possibilisation, disproportion, interpénétration: trois perspectives pour enquêter sur la productivité de la notion de forme de vie en sémiotique. Noveaux actes sémiotiques, Limoge, n. 115, p. 1-38, 2012. 
Disponível em: < http://revues.unilim.fr/nas/sommaire.php?id=4076>. Acesso em: 15 ago. 2012. (Atualmente, disponível em: <http:// epublications.unilim.fr/revues/as/2673>).

GREIMAS, A. J. De l'imperfection. Paris: Périgueux-Fanlac, 1987.

GREIMAS, A. J. Le beau geste. Recherches sémiotiques. Semiotic Inquiry, Montreal, v. 13, p. 21-35, 1993.

LANDOWSKI, E. Presenças do outro. São Paulo: Perspectiva, 2002.

LANDOWSKI, E. Passions sans nom. Paris: PUF, 2004.

LANDOWSKI, E. Para uma semiótica sensível. Educação \& Realidade, Porto Alegre, v. 30, p. 93-122, 2005.

MEYER, M. Prefácio. In: ARISTÓTELES. Retórica das paixões. São Paulo: Martins Fontes, 2000.

O CRUZEIRO. Rio de Janeiro, 18 set. 1954.

O CRUZEIRO. Rio de Janeiro, 2 out. 1954.

O CRUZEIRO. Rio de Janeiro, 25 out. 1954.

RECHERCHES Sémiotiques. Semiotic Inquiry, Montreal, v. 13, 1993.

SAUSSURE, F. Curso de lingüistica geral. São Paulo: Cultrix, 1970.

VOLLI, U. Semiótica da publicidade. Lisboa: Edições 70, 2003.

WITTGENSTEIN, L. Investigações filosóficas. São Paulo: Abril Cultural, 1975. (Série Os Pensadores). 